\title{
COLLABORATIVE WORK TO EVALUATE TOXICITY ON MALE REPRODUCTIVE ORGANS BY REPEATED DOSE STUDIES IN RATS 12) EFFECTS OF CYCLOPHOSPHAMIDE ON SPERMATOGENESIS
}

\author{
Takao WATANABE, Norikazu YAMAGUCHI, Tomohide AKIBA, \\ Masahiro TANAKA and Masayoshi TAKIMOTO \\ Department of Toxicology, Fuji Research Laboratories, Kowa Co., Ltd., \\ 332-1 Ohnoshinden, Fuji-city, Shizuoka 417-8650, Japan
}

(Received July 21, 2000 ; Accepted July 25, 2000)

\begin{abstract}
To determine what is an appropriate administration period for evaluation of the testicular toxicity of cyclophosphamide, the compound was administered orally to male Crj:(CD)SD rats at doses of $5,10,20$ and $40 \mathrm{mg} / \mathrm{kg} / \mathrm{day}$ for 2 weeks and at doses of $2.5,5$ and $10 \mathrm{mg} / \mathrm{kg} /$ day for 4 weeks.

All animals in the 2-week treatment group given $40 \mathrm{mg} / \mathrm{kg} / \mathrm{day}$ died during the treatment period. After repeated dosing, weights of testes and epididymides did not change significantly in either 2-week or 4-week treatment groups. On conventional histopathological examination, changes in spermatogonia were too subtle to allow simple quantitative evaluation. Therefore the quantitative analysis described by Matsui et al. (1995) was employed.

After 4-weeks treatment all types of germ cells decreased significantly in all stages of seminiferous tubules examined in the $10 \mathrm{mg} / \mathrm{kg} /$ day group. Spermatogonia type A in all stage seminiferous tubules examined and spermatogonia type B in stage V seminiferous tubules decreased significantly in the $5 \mathrm{mg} / \mathrm{kg} / \mathrm{day}$ group.

With 2-weeks treatment, spermatogonia type A in all stage seminiferous tubules examined were similarly decreased significantly in $10 \mathrm{mg} / \mathrm{kg} /$ day or more groups. Spermatogonia type B and pachytene spermatocytes in stage V, preleptotene spermatocytes in stage VII and zygotene spermatocytes in stage XII were decreased in $20 \mathrm{mg} / \mathrm{kg} /$ day group.

Sertoli cells and the Leydig cells and epididymides were not affected in any treatment group.

In conclusion, testicular toxicity induced by cyclophosphamide could be detectable after 2-weeks as well as after 4-weeks treatment if precise histopathological examination including quantitative analysis of spermatocytes are conducted.
\end{abstract}

KEY WORDS: Cyclophosphamide, Testis, Repeated dose, Reproductive toxicity, Rat

\section{INTRODUCTION}

Before administration of drug candidates to humans, results of repeated dose toxicity studies need to be evaluated. However, the period required for studies of reproductive toxicity was not harmonized in the International Conference on Harmonization of Technical Requirements for Registration of Pharmaceuticals Manufacturing Association [ICH] (ICH-M3 step IV guideline, 1997). Japan and the EU/US recommend 4 weeks and 2 weeks, respectively. This is because eval- uation of the effects on male reproduction is necessary before first clinical trials in Japan and it was considered that there are not enough data indicating that 2 weeks studies reliably allow detection of adverse effects (ICHM3 step IV guideline, 1997). Therefore, the Japanese Pharmaceuticals Manufacturing Association [JPMA] and the National Institute of Health Sciences [NIHS] have organized a validation study to obtain information and identify possible limitations of 2-week repeated dose toxicity studies for determination of effects on male reproductive organs in rats. As a part of this study, 
we administered cyclophosphamide for 2 weeks and compared the effects with those of a 4-weeks administration.

Cyclophosphamide, a functional alkylating agent, well known for its testicular toxicity, was selected for this study as a widely used anticancer and immunosuppressive drug. The pharmacological effects of alkylating agents result from cross-linking of DNA strands (Qiu et al., 1995) and interference with cell division in all rapidly proliferating tissues (Mietkiewski and Fichna., 1973). A number of reports have indicated that treatment with cyclophosphamide at $1-2 \mathrm{mg} / \mathrm{kg} /$ day over a period of 4-6 months causes oligozoospermia or azoospermia and increases follicule-stimulating hormone (FSH) levels (Fairley et al., 1972 ; Fukutani et al., 1981 ; Watson et al., 1985 ; Trasler et al., 1986). There have been many studies regarding the effects of cyclophosphamide on the male reproductive system in experimental animals (Miller, 1971). Treatment of mice with a single high dose of cyclophosphamide (50-100 $\mathrm{mg} / \mathrm{kg}$ ) was, for example, found to cause decrease in testicular weight (Pacchieroti et al., 1983), transient oligozoospermia (Lu and Meistrich, 1979), and DNA, RNA and protein synthesis in testes (Simura and Priestly, 1992 ; Lee and Dixon, 1972). Histopathological examination of rat testes has revealed that cyclophosphamide inhibits division and differentiation of spermatogonia (Mietkiewski and Fichna, 1973), but has no direct effects on Leydig or Sertoli cells (Velez et al., 1989). Since it has been reported that histopathological changes in the early phase of cyclophosphamide treatment occur only in spermatogonia and are very subtle, quantitative analysis of the cycle of spermatogenesis, a described by Matsui et al. (1995), was applied in this study.

\section{MATERIALS AND METHODS}

\section{Test substance}

Cyclophosphamide (cyclophosphamide monohydrate)(MW:279.1) was purchased from Sigma Chemical Company, (chemical name : 〔2H-1, 3, 2-oxazaphosphorine-2-amine $\mathrm{N}, \mathrm{N}$-bis(2-chloroethyl) tetrahydro-2-oxide, monohydrate] ).

\section{Animals and housing conditions}

Fifty male $\mathrm{CD}^{\circledR}$ (Sprague-Dawley derived) rats, 4 weeks of age, were purchased from Charles River Ltd., Japan (Hino, Shiga pref.). After the quarantine term, healthy animals were used for the study, and distributed into 9 groups using a computerized random sort program so that body weight means were comparable for each group $(n=5)$. The animals were housed singly in stainless steel-cages, in an air-conditioned room (temperature: $23 \pm 3^{\circ} \mathrm{C}$, relative humidity: $55 \pm 15 \%, 14-18$ air changes per hr, 12-hr light/dark cycle), and allowed free access to tap water and a laboratory animal diet (CE-2, CLEA Japan, Inc.). All surviving animals were sacrificed on the day after the last administration.

\section{Dose level and experimental design}

Male rats were treated orally daily with distilled water or cyclophosphamide at doses of 5,10,20 and 40 $\mathrm{mg} / \mathrm{kg}$ for 2 weeks, or at $2.5,5$ and $10 \mathrm{mg} / \mathrm{kg}$ for 4 weeks. The assignment to groups is shown in Table 1.

\section{Preparation and administration of the test drug}

Cyclophosphamide was diluted with distilled water and administered orally to male rats chronically for 2 or 4 weeks. Control animals were given the same amount of distilled water.

Table 1. Groups and doses.

\begin{tabular}{ccccc}
\hline Test substance & $\begin{array}{c}\text { Dose } \\
(\mathrm{mg} / \mathrm{kg})\end{array}$ & $\begin{array}{c}\text { Concentration } \\
(\mathrm{mg} / \mathrm{mL})\end{array}$ & $\begin{array}{c}\text { Administration } \\
\text { period (week) }\end{array}$ & $\begin{array}{c}\text { No. of Animals } \\
\text { male }\end{array}$ \\
\hline Control (distilled water) & 0 & 0 & 2 & 5 \\
Cyclophosphamide & 5 & 1.25 & 2 & 5 \\
Cyclophosphamide & 10 & 2.5 & 2 & 5 \\
Cyclophosphamide & 20 & 5 & 2 & 5 \\
Cyclophosphamide & 40 & 10 & 2 & 5 \\
Control (distilled water) & 0 & 0 & 4 & 5 \\
Cyclophosphamide & 2.5 & 1.25 & 4 & 5 \\
Cyclophosphamide & 5 & 1.25 & 4 & 5 \\
Cyclophosphamide & 10 & 2.5 & 4 & 5 \\
\hline
\end{tabular}


Effects of cyclophosphamide on spermatogenesis.

\section{Animal observation}

Animals were observed at least once a day for any mortality and toxicological signs.

\section{Body weight}

Body weights were recorded twice a week for all animals during the treatment period.

\section{Histopathology}

The testes and epididymides were fixed in formalin sucrose acetic acid solution, embedded in paraffin wax, sectioned, and stained with hematoxylin and eosin or by the periodic acid-Schiff's reaction. Histopathological examination was carried out considering testicular characteristics and the spermatogenetic stages. In addition, to confirm the presence or absence of testicular changes, a quantitative analysis of stage V, VII and XII seminiferous tubules was made for all surviving animals (6 tubules per animal) in the 2-week and 4week administration groups, using the simplified morphological method described by Matsui et al.(1995). Numbers of germ cells in a tubule were counted and expressed relative to Sertoli cells.

\section{Statistical analysis}

For the mean values of the respective observation items, homogeneity of variance was examined by the Bartlett method (Bartlett, 1937). If homogeneity was observed, one-way layout analysis of variance (ANOVA) was conducted. In case a significant difference was observed, a test was performed for comparison with the control group by the Dunnett method (Dunnett, 1955, 1964) (equal numbers of cases in the respective groups). If homogeneity was not observed, an $\mathrm{H}$ test of Kruskal-Wallis (Kruskal and Wallis, 1952, 1953) was conducted, and in case a significant difference was observed between groups, a rank sum test of the Dunnett type (equal numbers of cases in respective groups) was performed. Significant differences were tested between the control group and the respective groups for other values using the Wilcoxon's rank sum test. The significance levels are shown in tables, divided into $5 \%$ and $1 \%$ as $p$ values.

\section{RESULTS}

\section{2-Weeks treatment}

In the $40 \mathrm{mg} / \mathrm{kg} / \mathrm{day}$ group, all animals died within the administration period and after 1-week of dosing, hematuria was evident at a $100 \%$ incidence. Body weight gain was significantly decreased in the 10,20 and $40 \mathrm{mg} / \mathrm{kg} /$ day groups (Table 2). In the 20 $\mathrm{mg} / \mathrm{kg} /$ day group, absolute weights of the testes and epididymides did not change significantly (Table 3 ). However, on histopathological examination, there was a tendency for decrease in the numbers of spermatogonia. No changes in epididymides were observed in any of the treatment groups. On quantitative analysis, numbers of spermatogonia type A per Sertoli cell in a tubule were found to be significantly decreased at all stages examined in the 10 and $20 \mathrm{mg} / \mathrm{kg} / \mathrm{day}$ groups. In the latter, numbers of spermatogonia type B and pachytene spermatocytes at stage V, preleptotene spermatocytes at stage VII and zygotene spermatocytes at stage XII were also decreased significantly (Fig. 1).

\section{4-Weeks treatment}

No toxicological signs were observed except in one rat of the $10 \mathrm{mg} / \mathrm{kg} /$ day group, which died after the termination of the treatment period. Body weight gain was significantly decreased in the $10 \mathrm{mg} / \mathrm{kg} /$ day group (Table 2), but absolute weights of testes and epi-

Table 2. Body weight gain (g) of male rats treated with cyclophosphamide for 2 or 4 weeks.

\begin{tabular}{|c|c|c|c|c|c|c|}
\hline Dose $(\mathrm{mg} / \mathrm{kg})$ & 0 & 2.5 & 5 & 10 & 20 & 40 \\
\hline \multicolumn{7}{|l|}{2 weeks treatment } \\
\hline No. of males & 5 & & 5 & 5 & 5 & 5 \\
\hline Initial & $249 \pm 6$ & & $248 \pm 11$ & $252 \pm 7$ & $252 \pm 6$ & $248 \pm 14$ \\
\hline Final (Day 15) & $392 \pm 11$ & & $370 \pm 23$ & $359 \pm 12^{*}$ & $310 \pm 27 * * *$ & N.E. \\
\hline \multicolumn{7}{|l|}{4 weeks treatment } \\
\hline No. of males & 5 & 5 & 5 & 5 & & \\
\hline Initial & $201 \pm 7$ & $199 \pm 4$ & $199 \pm 6$ & $201 \pm 6$ & & \\
\hline Final (Day 29) & $385 \pm 21$ & $378 \pm 13$ & $362 \pm 28$ & $281 \pm 19^{* * *}$ & & \\
\hline
\end{tabular}

Mean \pm S.D. N.E.: Not examined.

$*: \mathrm{p}<0.05, * * *: \mathrm{p}<0.001$ : Significantly different from the control group. 
T. WATANABE et al.

didymides did not change significantly (Table 3 ). On histopathological examination, no remarkable changes were observed but there was a tendency for decrease in the numbers of spermatogonia in the $10 \mathrm{mg} / \mathrm{kg} /$ day group. No changes in epididymides were observed. With quantitative analysis, numbers of spermatogonia type A per Sertoli cell in a tubule were significantly decreased at all stages examined in the 5 and 10 $\mathrm{mg} / \mathrm{kg} / \mathrm{day}$ groups. In the $10 \mathrm{mg} / \mathrm{kg} /$ day group, numbers of spermatogonia type B, pachytene spermatocytes and round spermatids at stage $\mathrm{V}$, preleptotene spermatocytes, pachytene spermatocytes and round spermatids at stage VII and zygotene spermatocytes and pachytene spermatocytes at stage XII, respectively, were decreased significantly. In addition, spermatogonia type $\mathrm{B}$ at stage $\mathrm{V}$ were significantly decreased in the 5 $\mathrm{mg} / \mathrm{kg} /$ day group (Fig. 2).

\section{DISCUSSION}

The mechanisms by which the testes can be affected by drugs or toxicants have been classified as follows (Takahashi and Matsui, 1993): a) Direct action against the seminiferous epithelium; b) Hormonal indirect effects on spermatogenesis; c) Direct or indirect mechanisms affecting sperm; d) Circulatory disturbances affecting the testes; e) Other miscellaneous actions. It has generally been accepted that cyclophosphamide acts directly against the seminiferous epithelial spermatogonia type A lining the basement membrane in tubules not only in man but also in several experimental animals, including the rat (Russell and Russell, 1991 ; da Cunha et al., 1987).

The present study showed that a 4-week treatment with $10 \mathrm{mg} / \mathrm{kg} /$ day resulted in significant decrease in all types of germ cells in all stages of seminiferous tubules examined. Spermatogonia type A in all stages of seminiferous tubules and spermatogonia type B in stage $\mathrm{V}$ seminiferous tubules were similarly decreased significantly in the $5 \mathrm{mg} / \mathrm{kg} /$ day group. With 2-weeks treatment, spermatogonia type A in all stage seminiferous tubules examined were also decreased significantly in the $10 \mathrm{mg} / \mathrm{kg} / \mathrm{day}$ or greater groups. Spermatogonia type $B$ and pachytene spermatocytes in stage $V$, preleptotene spermatocytes in stage VII and zygotene spermatocytes in stage XII were decreased in $20 \mathrm{mg} / \mathrm{kg} /$ day group. Thus the results for 2 and 4 weeks treatment were comparable.

The first target cells of cyclophosphamide in the testes are the spermatogonia type A in the rat (Matsui et al., 1995 ; Takahashi and Matsui, 1993 ; Russell and Russell, 1991) and the mouse (Lu and Meistrich, 1979; da Cunha et al., 1987). The spermatogonia are the major proliferative cells of the testes and because of their high mitotic activity, they are the primary target for cyclophosphamide. Cells past the DNA-synthesizing stage, including spermatocytes, spermatids and spermatozoa, are generally resistant to cyclophosphamide (Notle et al., 1995).

Although necrotic spermatogonia at the base of seminiferous tubules were observed in male rats treated with cyclophosphamide at doses of $100 \mathrm{mg} / \mathrm{kg}$ for the first 2 days and $50 \mathrm{mg} / \mathrm{kg}$ thereafter 3 days by Takahashi and Matsui (1993), they were not found in

Table 3. Organ weights (g) for male rats treated with cyclophosphamide for 2 or 4 weeks.

\begin{tabular}{lccccc}
\hline Dose $(\mathrm{mg} / \mathrm{kg})$ & 0 & 2.5 & 5 & 10 & 20 \\
\hline 2 weeks treatment & 5 & & 5 & 5 & 5 \\
No. of males & $2.87 \pm 0.26$ & & $2.99 \pm 0.14$ & $3.12 \pm 0.18$ & $2.00 \pm 0.26$ \\
$\quad$ Testes & $0.76 \pm 0.09$ & & $0.83 \pm 0.05$ & $0.80 \pm 0.04$ & $0.79 \pm 0.04$ \\
$\quad$ Epididymides & $0.89 \pm 0.14$ & & $0.86 \pm 0.08$ & $0.82 \pm 0.18$ & $0.68 \pm 0.08$ \\
$\quad$ Seminal vesicle & $1.15 \pm 0.17$ & & $1.11 \pm 0.24$ & $0.94 \pm 0.20$ & $0.92 \pm 0.18$ \\
$\quad$ Prostate & 5 & & & & 5 \\
4 weeks treatment & $2.91 \pm 0.17$ & $3.16 \pm 0.23$ & $3.06 \pm 0.10$ & $2.79 \pm 0.24$ & \\
No. of males & $0.75 \pm 0.03$ & $0.83 \pm 0.06^{*}$ & $0.82 \pm 0.05$ & $0.70 \pm 0.05$ & \\
$\quad$ Testes & $0.82 \pm 0.14$ & $0.90 \pm 0.10$ & $0.79 \pm 0.03$ & $0.40 \pm 0.04^{*}$ & \\
$\quad$ Epididymides & $0.94 \pm 0.18$ & $1.08 \pm 0.18$ & $0.98 \pm 0.15$ & $0.64 \pm 0.07^{*}$ & \\
$\quad$ Seminal vesicle & & & 5 &
\end{tabular}

Mean \pm S.D.

$*$ : $<<0.05$ : Significantly different from the control group. 
Effects of cyclophosphamide on spermatogenesis.
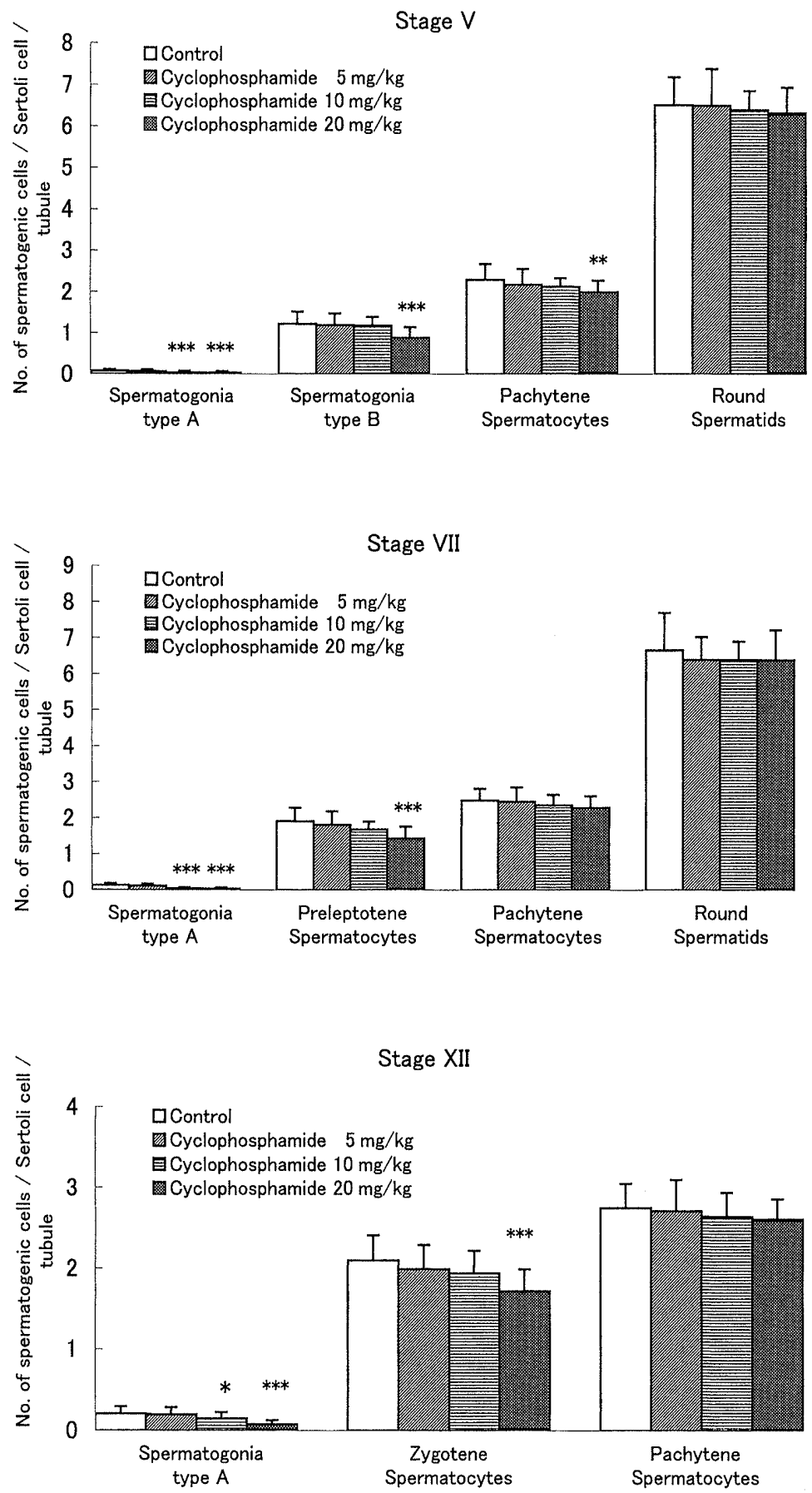

Fig. 1. Numbers of spermatogenic cells per Sertoli cell in seminiferous tubules of rats receiving 2-weeks administration of cyclophosphamide.

$*: \mathrm{p}<0.05, * *: \mathrm{p}<0.01, * * *: \mathrm{p}<0.001$ : Significantly different from the control group. 
T. WATANABE $e t a l$.
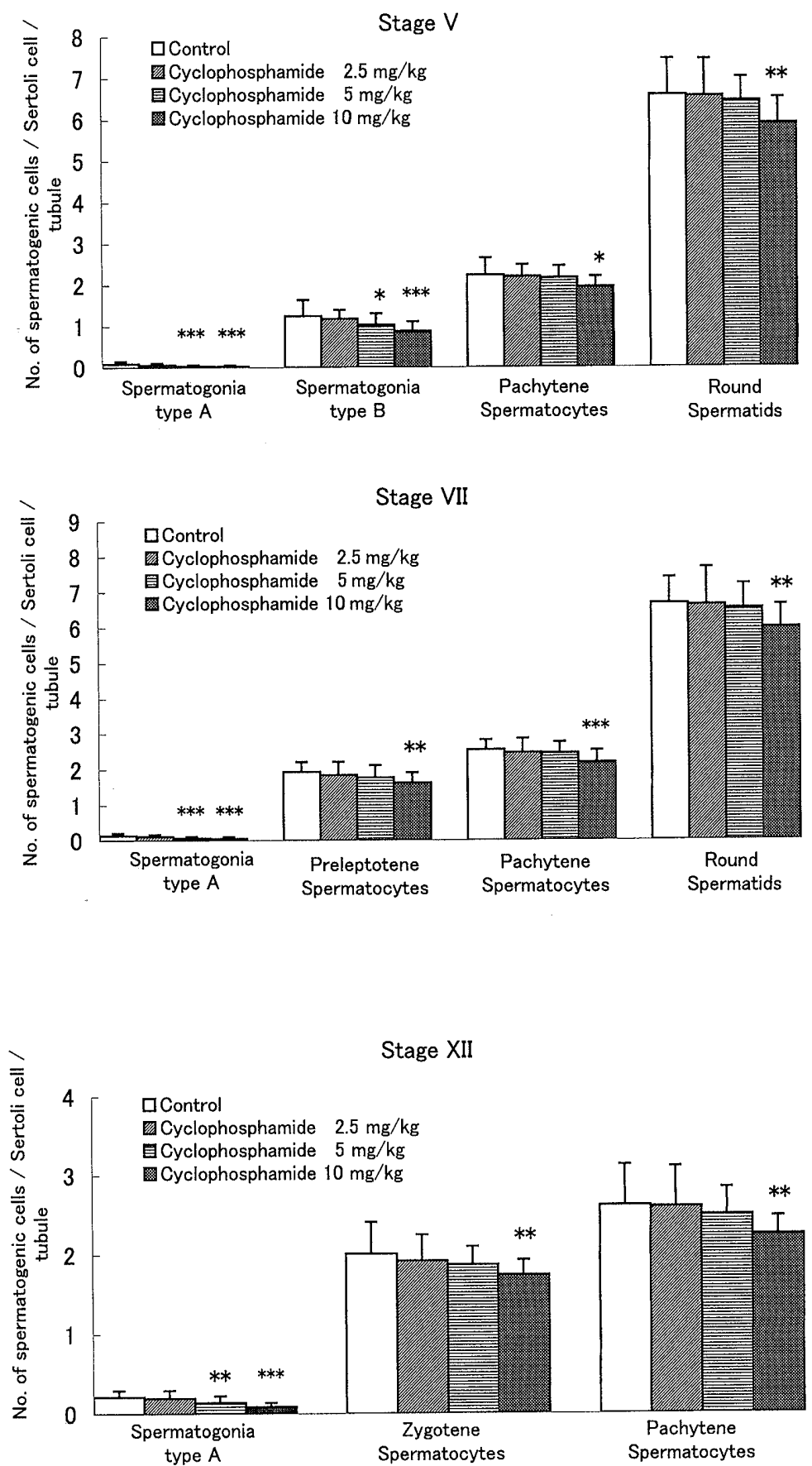

Fig. 2. Numbers of spermatogenic cells per Sertoli cell in seminiferous tubules of rats receiving 4-weeks administration of cyclophosphamide.

$*: \mathrm{p}<0.05, * *: \mathrm{p}<0.01, * * *: \mathrm{p}<0.001$ : Significantly different from the control group. 
Effects of cyclophosphamide on spermatogenesis.
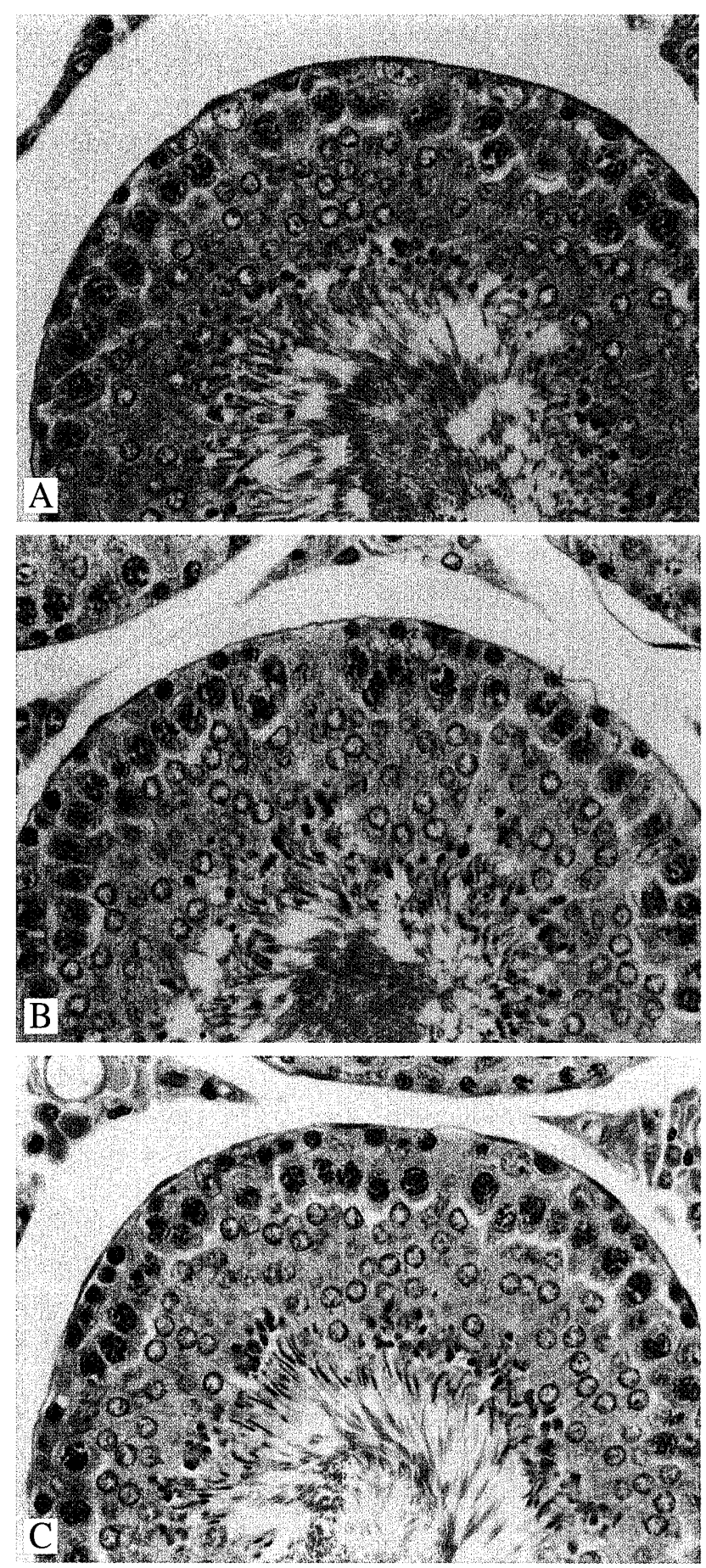

Photo 1. Histopathological findings for spermatogenesis in the testes in the 2week study.

(A): Normal stage VII seminiferous tubule in a control rat.

Note that many spermatogonia and preleptotene spermatocytes are situated on the basement membrane. HE stain. $\times 61$.

(B): Stage VII seminiferous tubule in a $10 \mathrm{mg} / \mathrm{kg} /$ day treated rat.

The number of spermatogonia on the basement membrane is decreased slightly. HE stain. $\times 61$.

(C): Stage VII seminiferous tubule in a $20 \mathrm{mg} / \mathrm{kg} /$ day treated rat.

Only a few spermatogonia can be seen on the basement membrane.

HE stain. $\times 61$. 
the present study, in line with the report of Higuchi et al. (1995). This difference in findings is presumably due to variation in the dose of cyclophosphamide or duration of treatment between the studies.

In addition, no changes were observed in Sertoli cells and other support cells in the testes or the epididymides, as demonstrated previously by Velez de la Calle et al. (1989).

In conclusion, the present study showed that testicular toxicity induced by cyclophosphamide is detectable after 2-weeks as well as 4-weeks treatment if a precise histopathological examination of the testes is conducted. Therefore, 2-weeks can be considered sufficient as an administration period for detection of the toxicity of cyclophosphamide on the male reproductive organs by repeated dose studies in the rat, if the dose is $10 \mathrm{mg} / \mathrm{kg} /$ day or greater.

\section{ACKNOWLEDGMENT}

We thank Dr. K. Mitsumori and Dr. K. Yasuhara (National Institute of Health Sciences) for their peer reviews and helpful suggestions.

\section{REFERENCES}

Bartlett, M.S. (1937): Properties of sufficiency and statistical test, Proc. Roy. Soc., A160, 268-282.

da Cunha, M.F., Meistrich, M.L. and Nader, S. (1987): Absence of testicular protection by a gonadotropinreleasing hormone analogue against cyclophosphamide-induced testicular cytotoxicity in the mouse, Cancer Res., 47, 1093-1097.

Dunnett, C.W. (1955): A multiple comparison procedure for comparing several treatments with a control. J. Am. Statist. Assoc., 50, 1096-1121.

Dunnett, C.W. (1964): New tables for multiple comparison with a control, Biometrics, 20, 482-491.

Fairley, K.F., Barrie, J.U. and Johnson, W. (1972): Sterility and testicular atrophy related to cyclophosphamide therapy, Lancet, 1, 568-569.

Fukutani, K., Ishida, H., Shinohara, M., Minowada, S., Niijima, T., Hijikata, K. and Izawa, Y. (1981): Suppression of spermatogenesis in patients with Behcet's disease treated with cyclophosphamide and colchicine, Fertil Steril, 36, 76-80.

Higuchi, H., Nakaoka, M., Katsuda, Y., Kawamura, S., Kato, T. and Matsuo, M. (1995): Collaborative assessment of optimal administration period and parameters to detect effects on male fertility in the rat: Effects of cyclophosphamide on the male reproductive system, J. Toxicol. Sci., 20, 239-249.

ICH-M3 step IV guideline (1997): Guideline for nonclinical safety studies for the conduct of human clinical trials for pharmaceuticals. 17 July 1997.

Kruskal, W.H. and Wallis, W.A. (1952): Use of ranks in one-criterion variance analysis, J. Amer. Statist. Assoc., 47, 583-621.

Kruskal, W.H. and Wallis, W.A. (1953): Errata, J. Amer. Statist. Assoc., 48, 907-912.

Lee, I.P. and Dixon, R.L. (1972): Antineoplastic drug effects on spermatogenesis studied by velocity sedimentation cell separation, Toxicol. Appl. Pharmacol., 23, 20-41.

Lu, C.C. and Meistrich, M.L. (1979): Cytotoxic effects of chemotherapeutic drugs on mouse testis cells, Cancer Res., 39, 3575-3582.

Matsui, H., Mitsumori, K., Yasuhara, K., Onodera, H., Shimo, T. and Takahashi, M. (1995): Morphological evaluation of cyclophosphamide testicular toxicity in rats using quantitative morphometry of spermatogenic cycle stages, J. Toxicol. Sci., 20, 407-414.

Mietkiewski, K. and Fichna, P. (1973): Influence of endoxan on the rat testis, Folia. Morph., 32, 445455.

Miller, D.G. (1971): Alkylating agents and human spermatogenesis, J. Am. Med. Assoc., 217, 16621668.

Notle, T., Harleman, J.H. and Jahn, W. (1995): Histopathology of chemically induced testicular atrophy in rats, Exp. Toxic Pathol., 47, 267-286.

Pacchieroti, P., Bellicampi, D. and Civitareale, D. (1983): Cytogenetic observations in mouse secondary spermatocytes on numerical and structural aberrations induced by cyclophosphamide in various stages of spermatogenesis, Mutat. Res., 19, 177-183.

Qiu, J., Hales, B.F. and Robaire, B. (1995): Damage to rat spermatozoal DNA after chronic cyclophosphamide exposure, Biol. Reprod., 53, 1465-1473.

Russell, L.D. and Russell, J.A. (1991): Short-term morphological response of the rat testis to administration of five chemotherapeutic agents, Am. J. Anat., 192, 142-168.

Simula, A.P. and Priestly, B.G. (1992): Species differences in the genotoxicity of cyclophosphamide and styrene in three in vivo assays, Mutation Res., 271, 49-58.

Takahashi, M. and Matsui, H. (1993): Mechanisms of testicular toxicity, J. Toxicol. Pathol., 6, 161-174.

Trasler, J.M., Hales, B.F. and Robaire, B. (1986): 
Effects of cyclophosphamide on spermatogenesis.

Chronic low dose cyclophosphamide treatment of adult male rats: Effect on fertility, pregnancy outcome and progeny, Biol. Reprod., 34, 275-283.

Velez de la Calle, J.F., de Queiroz, F., Garnier, D.H., Kercret, H., Folliot, R. and Jegou, B. (1989): Reproductive effects of the anticancer drug cyclophosphamide in male rats at different ages, Arch. Androl., 22, 251-263.

Watson, A.R., Rance, C.P. and Bain, J. (1985): Long term effects of cyclophosphamide on testicular function, Br. Med. J., 291, 1457-1460. 